\title{
A comparison of the performance of the ice and ocean tracking modes of the ERS-1 radar altimeter over non-ocean surfaces
}

\author{
R.F. Scott, S.G. Baker, C.M. Birkett, W. Cudlip, S.W. Laxon, D.R. Mantripp, J.A. \\ Mansley, J.G. Morley, C.G. Rapley, J.K. Ridley, F. Strawbridge and D.J. Wingham \\ Mullard Space Science Laboratory, University College London, Holmbury St. Mary, Dorking, Surrey
}

\begin{abstract}
The European Space Agency's ERS-1 radar altimeter is the first to include separate operating modes to optimise performance over both ocean and non-ocean surfaces. As part of the ERS-1 commissioning activities, we have carried out a study of the tracking performance of this instrument over non-ocean surfaces. Statistics for land ice, sea ice, arid lands, and inland water are presented. Performance in both operating modes is shown to be better than that of previous missions.
\end{abstract}

\section{Introduction}

During the last decade, the importance of non-ocean radar altimetry has been demonstrated. Applications include the study of ice sheet topography, mass balance and dynamics, sea ice extent, land and inland water studies, and their relationship to climate change (Rapley et al. 1983; Guzkowska et al. 1990; Laxon 1990).

The European Space Agency's ERS-1 remote sensing spacecraft carries a radar altimeter using two distinct operating modes, each featuring a novel control system. Space-borne radar altimeters are pulsed radars which must maintain the returned echo within a 'range window' consisting of a number of discrete echo samples, or 'range gates'. Parameters such as range, significant waveheight, windspeed, and backscatter coefficient can then be derived from the receiver automatic gain control (AGC) setting and the echo shape. To ensure that the returned echo will be positioned correctly within the range window, an $\alpha \beta$ tracking algorithm is used to predict the time of the next echo, and to smooth the range estimates (Cadzow, 1973). When the echo is correctly positioned within the range window, the instrument is said to be 'in-lock'. Over undulating surfaces, the tracker may be unable to follow the range and backscatter variations, and will effectively lose the leading edge of the echo from the range window. Such an event is known as 'loss of lock', and the altimeter must therefore re-acquire the surface.

The operating modes of the ERS-1 altimeter have rangegate resolutions of 3 and 12ns, defining different effective range window sizes. (Levrini and Rubertone 1984; Francis 1990). The tracking algorithm used with the 3ns gate resolution is known as the Sub-optimal Maximum Likelihood Estimator (SMLE) waveform fitting procedure (Levrini and Rubertone, 1984). The SMLE assumes the Brown ocean statistics model for the return echo, and this mode is

Copyright 1994 by the American Geophysical Union.

Paper number 94GL00178

0094-8534/94/94GL-00178\$03,00 consequently known as 'ocean mode' (Brown, 1977).

The alternative operating mode, known as 'ice mode', has a 12 ns range-gate resolution, and uses a centre of gravity tracking algorithm. This gives a larger range window which allows greater range variations to be followed. This mode was designed to provide in-lock data from surfaces which are poorly tracked by the ocean mode, especially over the continental ice sheets. It is possible to switch the ERS-1 altimeter between the ocean and ice modes several times per orbital revolution by ground command. This flexibility allows the use of the operating modes in such a way that the scientific return from the mission may be maximised.

Radar altimeters do not form an image swath, but make point measurements at or close to the nadir of the spacecraft as it follows its orbit. Coverage is built up over time as the orbit arcs cover the Earth's surface. The ERS-1 orbit latitude extrema extend to $\pm 82^{\circ}$, and for the first time, the whole of Greenland and most of Antarctica are covered.

It is important, in terms of coverage of in-lock data and tracking precision, to compare the performance of the ocean mode over non-ocean surfaces with that of the earlier missions, so that the applicability of the ERS-1 data to geophysical problems may be assessed. It is also necessary to assess the ice mode, which has not been implemented on a space-borne altimeter before. For a given application, we wish to know which of the two modes best suit the scientific requirements of ESA's Investigators, as an input to current and future mission planning.

As part of the ERS-1 Commissioning Phase activities, we have investigated the performance of the two tracking modes over non-ocean surfaces. Raw instrument data were made available by ESA from a period of operation following completion of the primary instrumental adjustments. The available data consisted of 6 days of data in ice mode (28th December 1991 to 3rd January 1992), and 3 days of data in ocean mode, covering the same ground tracks as the ice mode data, from 27th to 29th January 1992.

\section{Assessment Method}

The 'tracking mode flag' telemetered in the instrument data is not a reliable indicator of good data, since tracking may continue for some time when no return echo leading edge is present in the range gates (Strawbridge \& Laxon 1994). However, with the full instrument data, the individual $20 \mathrm{~Hz}$ waveforms are available, and a simple heuristic assessment method was used. The means of the gate values $\overline{P 1}, \overline{P 2}$ in the ranges 5 to 19 , and 20 to 64 respectively were calculated, as shown in figure 1 . A leading edge is deemed present in the range gates if $\overline{\mathrm{P} 1} \leq 0.25 \overline{\mathrm{P} 2}$. A 3 day repeat of data, in each of the two operating modes, was examined to assess the 
assess the percentage of data with a waveform leading edge present in the range gates.

assess the percentage of data with a waveform leading edge present in the range gates.

The masks used to separate sea ice, ocean, and non-ocean surfaces were approximate, being deliberately oversized to allow for acquisition effects, and because sea ice is variable in extent. The statistics are therefore accurate to approximately $\pm 5 \%$ for the given seasonal conditions.

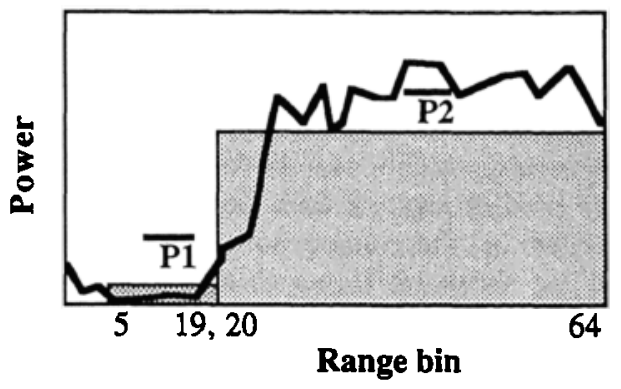

Figure 1. The heuristic quality assessment procedure. A waveform is deemed present if $\overline{\mathrm{P} 1} \leq 0.25 \overline{\mathrm{P} 2}$.

\section{Results and Discussion}

The results of the study are presented in Table 1 as percentages of $20 \mathrm{~Hz}$ data along the total orbit track which satisfy the assessment criteria for the areas of interest. There was great variability of performance over each surface type considered, as can be seen in Figure 2. Table 2 summarises the broadly defined scientific requirements, and compares measured instrument performance.

Over all non-ocean terrain, $74 \%$ of ice-mode data contained valid waveforms, whilst in ocean mode, $48 \%$ of data contained a valid waveform. The percentage of useful data in both tracking modes is therefore potentially greater than that from the GEOSAT and SEASAT instruments over similar surfaces, which returned approximately $28 \%$ and $34 \%$ respectively of good data (Rapley et al. 1987a; Wingham et al. 1992). However, the GEOSAT and SEASAT results are biased low because their orbits did not cover the ice sheet plateaux and ice shelves.

In the course of the study, two instrumental anomalies were discovered which caused data loss. Both anomalies were associated with handling of peaky pulses such as those seen over sea ice. The first affected mainly ocean mode, resulting in loss of the waveform from the rear of the range window and poor acquisition performance. The second affected mainly ice mode, and was associated with AGC saturation effects, resulting in loss-of-lock. The anomalies were reported to ESA, and a series of on-board software updates were performed. Due to ground-segment delays, it has not yet been possible to re-evaluate the statistics with waveform data. However some work has been done with Fast Delivery data and small runs of waveform data provided by ESA. Estimates of performance following the updates are shown in brackets in Table 1. Following the last update in June 1993, it appears from qualitative studies that all anomalies have now been succesfully addressed by ESA.
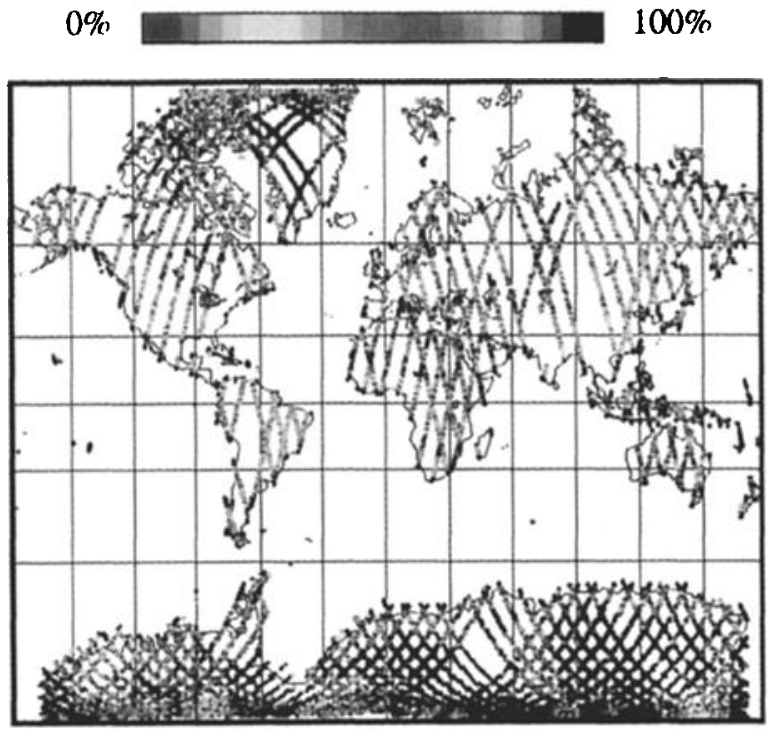

a) Ocean Mode

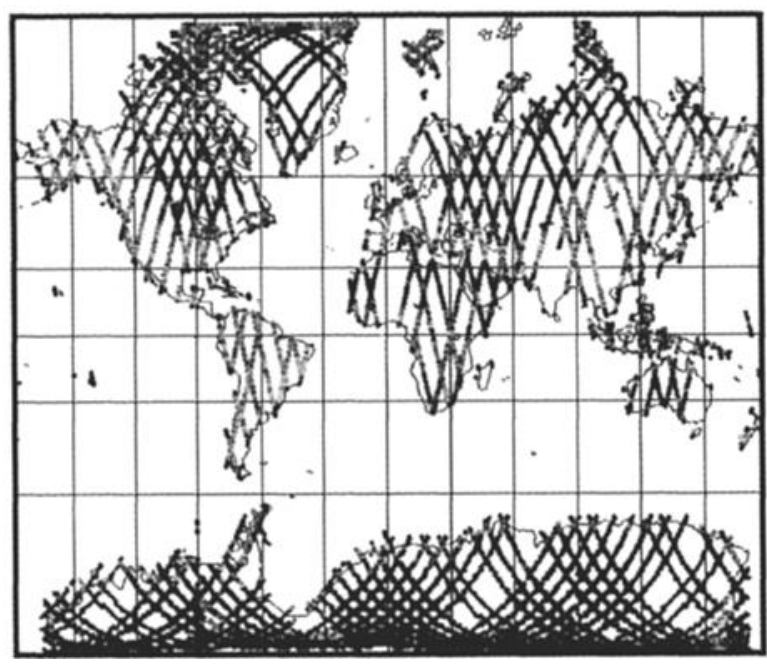

b) Ice Mode

Figure 2. Geographical variability of tracking performance of the ERS-1 altimeter, in ocean and ice mode over all land surfaces covered by the spacecraft orbit. Blue indicates tracking at $90 \%$ or better, and red indicates tracking at $10 \%$ or worse.

Over land ice, ice mode returned $92 \%$ of data containing a good waveform, whereas ocean mode returned $67 \%$. On the flat areas of the ice sheet plateaux and ice shelves, both modes returned approximately $100 \%$ of in-lock data. In areas of the plateaux containing undulations (Seko et al, 1992), ice mode retained lock in areas where ocean mode did not. In the ice sheet margins, ocean mode tracking was poor in many areas at approximately $10 \%$, whereas ice mode tracking was frequently better than $80 \%$.

Sufficient data were available to assess the precision of height, and height related altimeter measurements over the 
Antarctic ice sheet. Collinear repeat tracks from the flat polar plateau, undulating polar plateau, and the ice sheet margin, were available in both operating modes. The height precision was measured from collocated waveforms on the repeat tracks, by computing the retracked height differences of the individual waveforms. Retracking is the process used to correct the on-board range estimates for dynamic tracker offsets. This is necessary because the on-board tracker can only approximately position the tracking point on the half power point of the waveform leading edge, especially over rapidly varying terrain (Martin et al, 1983). The root-meansquare (RMS) of the individual height differences was determined from a 10-sample running mean of the retracked height estimates along the altimeter track.

Approximately half of the Antarctic plateau visible to the ERS-1 altimeter is free of undulations, as are large areas of the ice shelves. In these regions, repeat track analysis showed that the height precision in ocean mode was $0.28 \mathrm{~m}$ per $20 \mathrm{~Hz}$ sample (i.e. per $350 \mathrm{~m}$ ). In ice mode, precision was $0.49 \mathrm{~m}$ per $20 \mathrm{~Hz}$ sample. The precision in ice mode fell over areas of undulations to approximately $1.22 \mathrm{~m}$ per $20 \mathrm{~Hz}$ sample. Ocean mode frequently lost lock in these regions, as predicted by pre-launch simulations (Rapley and Griffiths 1984). At the ice sheet margins, ocean mode data rarely maintained lock. Icemode data had a precision of $6 \mathrm{~m}$ per $20 \mathrm{~Hz}$ sample in these areas.

The measured height precision in ice versus ocean mode is in accordance with theory which predicts that, in ice mode, the reduction of range resolution by a factor of 4 should result in a two-fold decrease in height precision. The accuracy of altimetric height measurements is usually dominated by orbit error, and the ionospheric and tropospheric delays must also be taken into account. In addition, signal penetration of the ice surface can introduce a bias in the height estimate of up to $1 \mathrm{~m}$ (Ridley and Partington 1988).

For climate change monitoring of the undulation-free areas of the ice sheet plateaux, it is necessary to be able to detect an elevation change of less than $0.05 \mathrm{~m} / \mathrm{year}$ (Robin 1983). By taking the mean of approximately 125 along-track $20 \mathrm{~Hz}$ range estimates, assuming a $\sqrt{\mathrm{N}}$ improvement in precision by averaging, the $2 \mathrm{~s}$ detection of $0.05 \mathrm{~m}$ change in a single year would be possible. At the margins, using ice mode data, an annual accumulation rate of $1 \mathrm{~m}$ would be detected if approximately 145 points of data in ice mode were averaged.
For ice sheet dynamics applications, measurement of surface slopes to approximately $0.15 \mathrm{~m} / \mathrm{km}$ precision is required (McIntyre and Drewry 1984). Using ocean mode data, measurement of surface slopes to $0.15 \mathrm{~m} / \mathrm{km}\left(0.01^{\circ}\right)$ on the flat areas of the plateaux may be attained by averaging slopes over 4 samples, corresponding to $1.3 \mathrm{~km}$. To achieve this slope precision in ice mode, the slopes must be averaged over $22 \mathrm{~km}$. Since ice sheet undulations typically have wavelengths less than this at approximately $10-20 \mathrm{~km}$ (Seko et al 1992), ice-mode data cannot be averaged simply for highprecision slope determination in areas of undulations. At the margins, ice-mode data may be used to measure slopes to $3.5 \mathrm{~m} / \mathrm{km}\left(0.2^{\circ}\right)$.

The study of tracking over lakes was limited by the small number of lake crossings in the available data set. The two tracking modes were seen to acquire and track the lakes equally well, given this limited dataset.

Due to lack of data, it was not possible to assess lake tracking precision by the same repeat track analysis as used for the ice sheets. The adopted method was to calculate the standard deviation of the retracked height measurements about a mean lake height. This method assumes that the lake is flat, and therefore ignores the effects of wind set-up and lake geoid variation. From the set of lake measurements, the tracker precision varied between 6 and $32 \mathrm{~cm}$ in ocean mode, and 5 and $106 \mathrm{~cm}$ in ice mode. The poorer tracker precisions in ice mode were correlated with incidences of tracker oscillation due to mountainous terrain surrounding the lakes.

To use lake levels as a proxy climate indicator, it is necessary to be able to measure these levels to an accuracy of approximately $\pm 25 \mathrm{~cm}$ (Mason et al, 1985). The measurements across the lake must therefore be averaged. In addition to the effects of the surrounding terrain, the accuracy of these lake level measurements is normally dominated by orbit error, and hence it is essential to reduce the orbit error to better than $\pm 10 \mathrm{~cm}$ if possible.

\section{Conclusions}

The performance of the ice and ocean tracking modes, combined with the ability to switch between them, suggests that the scientific potential of the ERS-1 altimeter mission is high over all land and land-ice surfaces. The ice mode provides a high percentage of good waveform data from

Table 1. ERS-1 tracking statistics from the First Ice Phase for all surface types studied.

\begin{tabular}{lllll}
\hline & \multicolumn{2}{c}{ Ocean Mode } & \multicolumn{2}{c}{ Ice Mode } \\
Mode & $\begin{array}{l}\text { Leading } \\
\text { Surface }\end{array}$ & edge track & $\begin{array}{l}\text { Mode } \\
\text { flag track }\end{array}$ & $\begin{array}{l}\text { Leading } \\
\text { edge track }\end{array}$ \\
\hline All non-ocean & $77 . \%$ & $48 . \%$ & $87 . \%$ & $74 . \%$ \\
Land Ice & $85 . \%$ & $67 . \%$ & $96 . \%$ & $92 . \%$ \\
Sea Ice (all) & $87 . \%$ & $65 . \%(75 \%)$ & $94 . \%$ & $87 . \%$ \\
Deserts & $81 . \%$ & $53 . \%(50 \%)$ & $96 . \%$ & $90 . \%$ \\
Wetlands & $74 . \%$ & $29 . \%(40 \%)$ & $85 . \%(90 \%)$ & $64 . \%(85 \%)$ \\
\hline
\end{tabular}

The "mode flag" column refers to all data flagged as in lock by the instrument tracking mode flag. The "leading edge" column refers to all data possessing a waveform with a leading edge, and therefore truly in lock. The figures in brackets are estimated values following the software modification to the on-board tracker carried out on the 23rd October, 1992, for ocean mode, and on the 4th December, 1992, for ice mode. The modifications did not affect adversely the performance over land ice and ocean. 
Table 2. A summary of the altimeter performance against broad scientific measurement requirements for selected surfaces.

\begin{tabular}{|c|c|c|c|c|c|c|c|c|c|}
\hline & \multicolumn{3}{|c|}{ Land ice plateau } & \multicolumn{3}{|c|}{ Land ice margins } & \multirow[b]{2}{*}{ required } & \multicolumn{2}{|l|}{ Lakes } \\
\hline & required & ocean & ice & required & acean & ice & & ocean & ice \\
\hline In-lock coverage & $100 \%$ & $>90 \%$ & $>90 \%$ & $100 \%$ & $\sim 10 \%$ & $-80 \%$ & $100 \%$ & $\mathrm{~nm}$ & $\mathrm{~nm}$ \\
\hline Height change & $.05 \mathrm{~m} / \mathrm{yr}$ & $125 \mathrm{pts}$ & - & $\operatorname{lm} / y r$ & - & $145 \mathrm{pts}$ & - & - & - \\
\hline Height precision & $<20 \mathrm{~cm}$ & $28 \mathrm{~cm}$ & $49 \mathrm{~cm}$ & $1 \mathrm{~m}$ & poor lock & $6 \mathrm{~m}$ & $<5 \mathrm{~cm}$ & $5-32 \mathrm{~cm}$ & $6-106 \mathrm{~cm}$ \\
\hline Height accuracy & $<20 \mathrm{~cm}$ & $30 \mathrm{~cm} / 3 \mathrm{pts} *$ & $50 \mathrm{~cm} / 8 \mathrm{pts}^{*}$ & $<1 \mathrm{~m}$ & - & $6 \mathrm{~m} / 40 \mathrm{pts} *$ & $\pm 25 \mathrm{~cm}$ & $34 \mathrm{~cm} / 2 \mathrm{pts} * \dagger$ & $1.1 \mathrm{~m} / 22 \mathrm{pts}^{*} \dagger$ \\
\hline Slope & $.01^{\circ}$ & $4 \mathrm{pts}$ & - & $.2^{\circ}$ & - & $1 \mathrm{pt}$ & geoid & $\mathrm{nm}$ & $\mathrm{nm}$ \\
\hline
\end{tabular}

The desired coverage is $100 \%$ in all cases. The height change values are accumulation rates which would need to be detected for climate monitoring purposes. The figures for height accuracy are quoted as the accuracy of a single $20 \mathrm{~Hz}$ measurement (left) and the number of points to be averaged to attain the measurement goal (right).

* indicates that an orbit error of $10 \mathrm{~cm}$ has been assumed in deriving altimetric height accuracy.

$\dagger \quad$ indicates that the worst case measured altimetric precision has been used.

$\mathrm{nm}$ indicates that no measurement was made during the current study.

- $\quad$ indicates that no requirement is applicable, or no measurement could be made or was applicable.

surfaces poorly tracked by previous altimeters. This will further increase the scope of non-ocean altimetry in the areas of ice and land topography, and ice mass-balance studies. The anomalies discovered during the course of the study have, for the most part, been successfully addressed by ESA.

Acknowledgement. This work was in part funded under contract RAE 1B/44 of the Defence Research Agency, as a subcontract of ESA contract 9575/91/HGE-I. We also acknowledge the support of National Remote Sensing Centre Ltd, and Earth Observation Sciences Ltd.

\section{References}

Brown, G.S., 'The average impulse response of a rough surface and its applications', IEEE Transactions on Antennas and Propagation, AP-26, 3, pp 472-482, 1977.

Cadzow, J.A., 'Discrete time systems', Prentice-Hall, 1973.

Francis, C. R. 'RA data chains' (in ERS-1 satellite to ground segment interface specification: ER-IS-ESA-GS-0001). European Space Agency, Noordwijk, 1990.

Guzkowska, M. A. J., Rapley, C.G., Ridley, J.K., Cudlip, W., Birkett, C.M., Scott, R.F., 'Developments in inland water and land altimetry', European Space Agency. ESA Report No. $C R-7893 / 88 / F / F L, 1990$.

Laxon, S. 'Seasonal and inter-annual variations in Antarctic sea ice extent as mapped by radar altimetry.' Geophys. Res. Lett. 17(10): 1553-1556, 1990.

Levrini, G. and F. Rubertone, "The ERS-1 radar altimeter instrument. ERS-1 Radar Altimeter data products', $S P-22 I$ : ESA Scientific and Technical Publications Branch. 17-22, 1984.

Martin, T.V., Zwally, H.J., Brenner, A.C., Bindschadler, R.A., Analysis and retracking of continental ice sheet radar altimeter waveforms. J. Geophys. Res., 88, NoC3, 1608-1616, 1983.

Mason, I.M., Rapley, C.G., Street-Perrott, F.A., Guzkowska, M.A.J., ERS-1 Observations of lakes for climate research. Proc EARSeL/ESA Symposium, European Remote
Sensing Opportunities, Strasbourg, European Space Agency, pp 235-241, 1985.

McIntyre, N.F., Drewry, D.J., 'Modelling ice-sheet surfaces for ERS-1's Radar Altimeter', ESA Journal, 8, pp 261-274, 1984.

Rapley, C.G., Griffiths, H.D., Squire, V.A., Lefebvre, M., Birks, A.R., Brenner, A.C. and 17 co-authors, 'A study of satellite radar altimeter operation over ice covered surfaces' ESA Contract Report No 5182/82/F/CG/(SC), European Space Agency, 1983.

Rapley, C. G. and Griffiths. H.D. 'Modelling of altimeter tracking over topographic surfaces', in ERS-1 Radar

Altimeter Data Products, SP-221 European Space Agency, pp.177-180, 1984.

Ridley, J.K., and Partington, K.C., A model of satellite radar altimeter return from ice sheets, Int. J. Remote Sensing, 9, No. 4, 601-624, 1988.

Robin, $\mathrm{G}$ de $\mathrm{Q}$, in: 'The climate record in the polar ice sheets', edited by Robin, G de Q, Cambridge University Press, pp 94-97, 1983.

Seko, K., Furukawa, T., Watanabe, O. and Nishio, F., 'Undulating topography on the Antarctic ice sheet revealed by image sensors', Proc. IGS symposium, Boulder, Colorado, USA, 1992.

Strawbridge, F. and Laxon, S.W., 'ERS-1 Altimeter Fast Delivery Data Quality Flagging Over Land Surfaces' Geophys. Res. Lett. 1994 in press.

Wingham, D. J. , Berry, P.A.M., Birkett, C.M., Devayya, R., Gilbert, L.K., Jackson, D., Palmer, D.E., Rapley, C.G., and Wolf, M., 'The GEOSAT Altimeter Dataset', Defence Research Agency Agreement No: 2047/144/EXR3, 1992.

(Received 14th January 1993;

Revised 26th August 1993;

Accepted 22 November 1993) 